\title{
Lixisenatide Attenuates the Detrimental Effects of Amyloid $\beta$ Protein on Spatial Working Memory and Hippocampal Neurons in Rats
}

\author{
Hong-Yan Cai ${ }^{1}$, Zhao-Jun Wang ${ }^{2}$, Christian Hölscher ${ }^{3}$, Li Yuan $^{2}$, Jun Zhang ${ }^{2}$, Peng Sun ${ }^{1}$, Jing Li $^{1}$, Wei \\ Yang $^{2}$, Mei-Na Wu ${ }^{2}$, Jin-Shun $\mathrm{Qi}^{2 *}$ \\ ${ }^{1}$ Department of Microbiology and Immunology, Shanxi Medical University, Taiyuan 030001, \\ China \\ ${ }^{2}$ Department of Physiology, Shanxi Medical University, Taiyuan 030001, China \\ ${ }^{3}$ Division of Biomed and Life Sciences, Faculty of Health and Medicine Lancaster University, \\ Lancaster, LA1 4YQ, UK
}

published in Behavioural Brain Research (2016) DOI: 10.1016/j.bbr.2016.10.033.

\author{
*Corresponding author: \\ Jin-Shun Qi, Ph. D \& Prof. \\ Department of Physiology, Shanxi Medical University, \\ Taiyuan, Shanxi 030001, China \\ Tel: 86-351-413-5091 \\ E-mail: jinshunqi2009@163.com
}

Grant information:

1) Grant sponsor: The National Natural Science Foundation of China, Grant number: 31471080, 31271201; 2) Grant sponsor: Higher School Science and Technology Innovation Project of Education Department in Shanxi Province (2015152); 3) Grant sponsor: The Doctoral Startup Research Fund of Shanxi Medical University (03201402); 4) Grant sponsor: 331 Science and Technology Cultivation Fund of Basic Medical College in Shanxi Medical University (201403); 5) Grant sponsor: The Youth Research Fund of Shanxi Medical University (02201308) 


\begin{abstract}
Type 2 diabetes mellitus ( T2DM) is a risk factor of Alzheimer's disease (AD), which is most likely linked to impairments of insulin signaling in the brain. Hence, drugs enhancing insulin signaling may have therapeutic potential for AD. Lixisenatide, a novel long-lasting glucagon-like peptide 1 (GLP-1) analogue, facilitates insulin signaling and has neuroprotective properties. We previously reported the protective effects of lixisenatide on memory formation and synaptic plasticity. Here, we describe additional key neuroprotective properties of lixisenatide and its possible molecular and cellular mechanisms against AD-related impairments in rats. The results show that lixisenatide effectively alleviated amyloid $\beta$ protein (A $\beta$ ) 25-35-induced working memory impairment, reversed A 325 -35-triggered cytotoxicity on hippocampal cell cultures, and prevented against A $325-35$-induced suppression of the Akt-MEK1/2 signaling pathway. Lixisenatide also reduced the A $\beta 25-35$ acute application induced intracellular calcium overload, which was abolished by U0126, a specific MEK1/2 inhibitor. These results further confirmed the neuroprotective and cytoprotective action of lixisenatide against $A \beta$-induced impairments, suggesting that the protective effects of lixisenatide may involve the activation of the Akt-MEK1/2 signaling pathway and the regulation of intracellular calcium homeostasis.
\end{abstract}

Key words: Lixisenatide ; Amyloid $\beta$ protein; Working memory; Cell viability; Akt-MEK1/2 signal pathway; Intracellular calcium concentration 


\section{Introduction}

Alzheimer's disease (AD) is a progressive neurodegenerative disorder, afflicting more than 40 million people all around the world (World Alzheimer Report, 2015). It is characterized by memory loss and cognitive decline (Selkoe, 2001). One of the prominent events in the pathogenesis of $\mathrm{AD}$ is the formation of abundant deposits of senile plaques composed of amyloid $\beta$ protein (A $\beta$ ) (Arnold et al., 1991; Thal et al., 2002). The toxicity of $\mathrm{A} \beta$ has been widely reported. For example, prolonged infusion of synthetic A $\beta$ into the brain impaired learning and memory in rats, including working memory and place learning in the eight-arm radial maze, Y-maze and water maze (Nitta et al., 1997; Stepanichev et al., 2005); A $\beta$ destabilized neuronal calcium homeostasis, altered cellular ionic activity, and rendered neurons more vulnerable to toxic stimuli in human cerebral cortical cell cultures (Fraser et al., 1997; LaFerla, 2002); A $\beta$ acutely impaired synaptic functions when added to hippocampal slices or slice cultures (Li et al., 2009). Not only full length A $\beta$ but also its fragments, such as A $\beta 25-35$ and A $\beta 31-35$, could induce apoptosis in cultured cortical neurons (Yan et al., 1999), in vivo LTP (Gault and Holscher, 2008), and cognitive deficits in rats (Alkam et al., 2007; Yuan et al., 2016). Unfortunately, effective neuroprotective strategies against $\mathrm{A} \beta$ neurotoxicity are still lacking.

Epidemiological studies found a clear correlation between type 2 diabetes mellitus (T2DM) and $\mathrm{AD}$, in which $\mathrm{T} 2 \mathrm{DM}$ has been identified as a risk factor for $\mathrm{AD}$ and the insulin resistance in the brain might initiate or accelerate the development of AD (Luchsinger et al., 2004; Ohara et al., 2011; Talbot et al., 2012). Based on these observations, it might be a promising strategy to normalize insulin signaling in the brain for the prevention and treatment of AD. Glucagon-like peptide 1 (GLP-1), an incretin hormone, and GLP-1 analogues that are protease resistant, have been reported to be able to cross the blood-brain barrier (BBB) and it facilitates insulin signaling (Gengler et al., 2012; Holscher, 2014a; Hunter and Holscher, 2012a). Furthermore, it has been found that GLP-1 and the GLP-1 receptor (GLP-1R) are expressed in the rodent central nervous system (Cork et al., 2015; Merchenthaler et al., 1999), especially the memory-related brain regions, such as the hippocampus (Cork et al., 2015; During et al., 2003; Hamilton and Holscher, 2009). More 
importantly, GLP-1 possesses neurotrophic properties (Holscher, 2014b; Perry et al., 2002b), and could protect neurons against glutamate-induced apoptosis and even decrease endogenous $\mathrm{A} \beta$ accumulation in cellular and animal models of $\mathrm{AD}$ ( $\mathrm{Li}$ et al., 2010; McClean et al., 2011b). However, endogenous GLP-1 is broken down quickly and lasts for only several minutes in blood plasma, which greatly limits its application in clinical practice (Deacon et al., 1995). Currently, several GLP-1 mimetics are on the market (e.g. exendin-4 (Byeatta), liraglutide (Victoza) and lixisenatide (Lyxumia)). They have been engineered and developed to resist protease degradation (Christensen et al., 2011; Holst, 2004; Madsbad et al., 2008; Vilsboll, 2009). These GLP-1R agonists enhance cognition and reduce blood glucose levels in T2DM models (Gumuslu et al., 2016), but do not affect blood glucose levels in non-diabetic animals or people (McClean and Holscher, 2014). It has been reported that exendin-4 enhanced nerve growth factor (NGF)-induced cell differentiation into neurons (Perry et al., 2002a), and showed pronounced neuroprotective and anti-inflammatory effects in middle-aged diabetic animals (Darsalia et al., 2012), reversed T2DM-induced neuronal pathology in the piriform cortex of the rat (Lietzau et al., 2016), and antagonized $A \beta 1-42$-induced suppression of hippocampal long-term potentiation in rats (Wang et al., 2015). Liraglutide also enhanced synaptic plasticity in the hippocampus of the APP/PS1 AD mouse model (McClean et al., 2010), reduced the chronic inflammation response (McClean et al., 2011a; Parthsarathy and Holscher, 2013), and ameliorated working memory impairment in the $\mathrm{A} \beta$-induced AD mouse model (Qi et al., 2016). Lixisenatide, a novel long-lasting GLP-1 analogue, has a higher permeability across the BBB and greater biological activity than exendin-4 and liraglutide (Hunter and Holscher, 2012b; Liu et al., 2015). Our previous studies (Cai et al., 2014) showed that lixisenatide prevented Aß25-35 -induced spatial memory deficits and hippocampal LTP suppression in rats. In the present study, we first observed the effects of lixisenatide on A $\beta$-induced deficits in spatial working memory of rats and cultured cell viability by using $\mathrm{Y}$ maze test and primary hippocampal neuronal cultures. Furthermore, the molecular and cellular mechanisms underlying the neuroprotective role of lixisenatide were investigated by using the Western blotting technique and intracellular calcium imaging. 


\section{Methods}

\subsection{Animals and drugs}

Adult male Sprague Dawley (SD) rats (200-230 g) were provided by the Animal Research Center of Shanxi Medical University. All animal handling and procedures accorded with the guidelines of the Shanxi Animal Research Ethics Committee. During experiments, rats were kept at controlled room temperature $\left(20-24^{\circ} \mathrm{C}\right)$ and humidity $(60 \%-$ 80\%). A $\beta 25-35$ and lixisenatide (Sigma, St. Louis, MO, USA) were stored in dry form and dissolved in saline $(5 \mathrm{nmol} / \mu \mathrm{l})$ before experiments.

\subsection{Intrahippocampal injection}

Intrahippocampal injection was performed as previously described (Ryu and McLarnon, 2006, 2008). In brief, SD rats were anesthetized (chloral hydrate, $0.3 \mathrm{~g} / \mathrm{kg}$, i.p.) and placed in a stereotaxic apparatus (Narishige, Tokyo, Japan). Lixisenatide ( $5 \mathrm{nmol} / \mu \mathrm{l})$ or vehicle $(0.9 \% \mathrm{NaCl})$ and $\mathrm{A} \beta 25-35(5 \mathrm{nmol} / \mu \mathrm{l})$ or saline $(0.9 \% \mathrm{NaCl})$ were bilaterally injected into the hippocampi (anterior-posterior: $-3.0 \mathrm{~mm}$; medial-lateral: $\pm 2.2 \mathrm{~mm}$; dorso-ventral: $-3.0 \mathrm{~mm}$, from bregma), with an injection rate of $0.2 \mu \mathrm{l} / \mathrm{min}$ under the control of a micropump (KD Scientific, Inc, KDS310 Plus, USA). In co-application group, lixisenatide was injected 15 min before A $\beta 25-35$ application. To make sure the drugs were fully dispersed into the hippocampus, a 5 min-retention of the injection syringe in the brain was given after every injection.

\section{3 Y maze test}

Spontaneous alternation of Y maze was performed to examine the spatial working memory of rats. Rats were examined 10 days after drug administration. The Y maze has three redial arms $(\mathrm{A}, \mathrm{B}, \mathrm{C})$ with the same angle $\left(120^{\circ}\right)$ between arms. Each arm is $45 \mathrm{~cm}$ long and $12 \mathrm{~cm}$ high. Rats were put into the junction of three arms and allowed to move freely for $8 \mathrm{~min}$ session. The entries of rats into each arm were recorded and every entry different from last two entries was considered as a successful alternation. The alternation 
percentage was calculated according to the following: [(number of alternations)/(total number of arm entries -2$)] \times 100(\%)$ (Iwai et al., 2014).

\subsection{Primary hippocampal neuronal cell culture}

Primary hippocampal formation cultures were prepared from 24 hours postnatal SD rats. Briefly, pups were anesthetized with ether, and sterilized in $75 \%$ ethanol. Rat brains were quickly removed into ice-cold dissection solution. The hippocampi were stripped and cut into small pieces (each cube $<1 \mathrm{~mm}^{3}$ ). The tissue pieces were incubated with $0.125 \%$ trypsin at $37^{\circ} \mathrm{C}$ for $15-20 \mathrm{~min}$, and then complete culture medium was added to stop enzymatic reaction. Single-cell suspensions were obtained by mechanical dissociation using a Pasteur pipette with a fire-polished tip in complete culture medium, and then filtered through a 200 mesh nylon screen, centrifuged for $5 \mathrm{~min}$ at $1000 \mathrm{rpm}$. The cells at the bottom were resuspended with fresh complete culture medium and plated on poly-D-lysine coated 96-well plates and $35 \mathrm{~mm}$ culture dishes (Corning Inc) at a density of $5 \times 10^{5}$ cells $/ \mathrm{ml}$. Cultures were maintained in $5 \% \mathrm{CO}_{2}$ at $37^{\circ} \mathrm{C}$ in complete culture medium for $6 \mathrm{~h}$. The culture media were then changed to serum-free B27/neurobasal medium. Afterward, half of the culture medium was replaced with fresh serum-free B27/neurobasal medium every 3 days. 7-10 days after plating, the mature cells were used for further experimental observation. The experiment was all carried out under sterile condition.

\subsection{Cell viability assay}

To assess the rate of cell viability, cell counting kit-8 (CCK-8) and lactate dehydrogenase (LDH) were used. Briefly, cells were inoculated in 96-well plates. After 7-10 days, cells were incubated with A $\beta 25-35(10 \mu \mathrm{M})$ for 24 hours. In co-application group, Lixisenatide $(100 \mu \mathrm{M})$ were applied 24 hours before A $\beta 25-35$ treatment. Six wells were used for each sample, and each experiment was repeated three times. CCK-8 solution $(10 \mu \mathrm{l})$ was added to each well, then cells were incubated at $37^{\circ} \mathrm{C}$ for $2 \mathrm{~h}$. The absorbance of samples was measured by a microplate reader (SpectraMAX 190, Molecular Devices, 
Sunnyvale, CA) at $450 \mathrm{~nm}$. Supernatant was collected to measure the LDH (a stable cytosolic enzyme, which is released upon cell lysis) release according to the manufacturer's instructions.

\subsection{Western blotting}

Cell lysate containing $5 \mu \mathrm{g}$ of protein was separated on 4-12\% gel and electrophoresed in running buffer at $200 \mathrm{mV}$ for $35 \mathrm{~min}$, followed by transfer to polyvinylidenedifluoride membrane. The membrane was washed in 1X TBST and blocked in 5\% skimmed milk for 2 $\mathrm{h}$ at $25^{\circ} \mathrm{C}$. The membrane was then incubated with anti-pAkt (Ser473) (1:400) and anti-phospho-MEK1/2 (Ser217/221) (1:1000) antibodies at $4{ }^{\circ} \mathrm{C}$ overnight. All the primary antibodies used were generated in rabbit. $\beta$-actin was used as loading control. The membrane was incubated with 1:400 horseradish peroxidase-conjugated anti-rabbit IgG for $2 \mathrm{~h}$ at $25^{\circ} \mathrm{C}$. Relative density of bands was calculated.

\subsection{Confocal calcium imaging}

Intracellular free $\mathrm{Ca}^{2+}$ was measured with fluorescent dye Fluo-3/AM utilizing confocal laser scanning microscope (CLSM) (Olympus, FV-1000). Briefly, cultures were washed three times with balanced salt solution. Then, cells were loaded with the same solution containing $5 \mu \mathrm{M}$ fluorescent $\mathrm{Ca}^{2+}$ indicator dye Fluo-3/AM for $1 \mathrm{~h}$ in a dark place at $37^{\circ} \mathrm{C}$. To remove the extracellular Fluo-3/AM, the loaded cells were rinsed three times with the balanced salt solution. Live video calcium images of selected neurons under microscopic field were recorded with a CLSM. Excitation wavelength of $488 \mathrm{~nm}$ and emission wave length of $526 \mathrm{~nm}$ were selected for the Fluo-3/AM fluorescence. Images were typically collected at $10-\mathrm{sec}$ interval and recorded at least $20 \mathrm{~min}$. The fluorescence intensities associated with a given cell were determined from digitized images and the data were processed using Olympus image analysis software. The experiment was carried out in the dark. 


\subsection{Data analysis}

All values in the experiments were expressed as means \pm standard errors (SEM). The SPSS 13.0 and SigmaPlot 11.0 statistical packages were used for statistical analyses. The data from Y maze test, cell viability assay and western blotting were examined by a two-way repeated measures analysis of variance (ANOVA). The data from confocal calcium imaging was performed by using one-way ANOVA and Student-t test. The statistical significance level was defined as $\mathrm{p}<0.05$.

\section{Results}

\subsection{Lixisenatide reversed the Aß25-35-induced impairment of spatial working memory}

Two-way ANOVA showed A $\beta 25-35$ injection and lixisenatide pretreatment had significant main effects on the spontaneous alternation of rats $(\mathrm{A} \beta 25-35: F(1,36)=139.156$, $P<0.001$; lixisenatide: $F(1,36)=137.718, P<0.001$; $\mathrm{A} \beta 25-35$ by lixisenatide: $F(1,36)=$ 163.483, $P<0.001)$. As shown in the Figure 1A, Tukey's post hoc tests showed that A $325-35$ significantly reduced the percentage of right turns of rats $(P<0.001, n=10)$ and lixisenatide reversed this detrimental effect $(P<0.001, \mathrm{n}=10)$. At the same time, the total arm entries of rats did not show any significant difference among these groups $(P>0.05$; Figure 1B).

\subsection{Lixisenatide inhibited the Aß25-35-induced cytotoxicity on cultured hippocampal cells}

Two-way ANOVA showed A $\beta 25-35$ injection and lixisenatide pretreatment had significant main effects on the viability of cultured hippocampal formation by CCK-8 assay $(\mathrm{A} \beta 25-35: F(1,36)=382.892, P<0.001 ;$ lixisenatide: $F(1,36)=180.696, P<0.001$; A $325-35$ by lixisenatide: $F(1,36)=203.032, P<0.001)$. As shown in the Figure $2 \mathrm{~A}$, Tukey's post hoc tests showed that A $\beta 25-35$ significantly decreased the viability of hippocampal formation cultures $(P<0.001, \mathrm{n}=10)$ and lixisenatide reversed this toxicity 
effect $(P<0.001, \mathrm{n}=10)$. Two-way ANOVA showed A $\beta 25-35$ injection and lixisenatide pretreatment had significant toxic effects on the viability of cultured hippocampal formation by LDH assay $(\mathrm{A} \beta 25-35: F(1,36)=330.942, P<0.001$; lixisenatide: $F(1,36)=183.66$, $P<0.001$; A $\beta 25-35$ by lixisenatide: $F(1,36)=111.299, P<0.001)$. As shown in the Figure 2B, Tukey's post hoc tests showed that A $\beta 25-35$ significantly induced the death of cultured hippocampal formation $(P<0.001, \mathrm{n}=10)$ and lixisenatide weakened this bad effect $(P<0.001$, $\mathrm{n}=10)$.

\subsection{Lixisenatide relieved the Aß25-35-induced suppression of the Akt-MEK1/2 signaling pathway}

The neuroprotection of lixisenatide might be related to the Akt-MEK1/2 signal pathway. Two-way ANOVA showed A $\beta 25-35$ injection and lixisenatide pretreatment had significant main effects on the level of pAkt $(\mathrm{A} \beta 25-35: F(1,36)=6.984, P<0.05$; lixisenatide: $F(1,36)=8.492, P<0.05$; A $\beta 25-35$ by lixisenatide: $F(1,36)=9.398, P<0.05)$. As shown in the Figure 3A, Tukey's post hoc tests showed that A $325-35$ significantly decreased the level of pAkt $(P<0.05, \mathrm{n}=10)$ and lixisenatide reversed this decrease $(P<0.05$, $\mathrm{n}=10$ ). Two-way ANOVA showed A $25-35$ injection and lixisenatide pretreatment had significant main effects on the level of pMEK1/2 (A $325-35: F(1,36)=7.429, P<0.05$; lixisenatide: $F(1,36)=4.499, P<0.05$; A $\beta 25-35$ by lixisenatide: $F(1,36)=5.409, P<0.05)$. As shown in the Figure 3B, Tukey's post hoc tests showed that A $\beta 25-35$ induced a significant decrease in the level of MEK1/2 $(P<0.05, \mathrm{n}=10)$ and this decrease was reversed by lixisenatide $(P<0.05, \mathrm{n}=10)$.

\subsection{Lixisenatide significantly protected against the A $325-35$-induced elevation of $\left[\mathrm{Ca}^{2+}\right]_{i}$, which was abolished by a MEK1/2 inhibitor}

The cell mechanism of $A \beta$-induced neurotoxicity involves in the perturbation of $\mathrm{Ca}^{2+}$ homeostasis. Firstly, we investigated the change of $\left[\mathrm{Ca}^{2+}\right]_{i}$ level in rat primary cultured hippocampal neuron by applying $10 \mu \mathrm{M} A \beta 25-35$. As shown in the Figure $4 \mathrm{~B}$, the relative fluorescent intensity at resting condition in the control group $(n=20)$ was very stable, nearly 
showing as a straight horizontal line. After application of $\mathrm{A} \beta 25-35(\mathrm{n}=20)$, the fluorescent intensity in most of neurons gradually and persistently increased during all of recording time. Figure $4 \mathrm{C}$ showed the relative fluorescent intensity values of $\left[\mathrm{Ca}^{2+}\right]_{\mathrm{i}}$ in different experimental groups at 20 min after application of $A \beta 25-35$. Obviously, $A \beta 25-35$ increased the relative fluorescent intensity of $\left[\mathrm{Ca}^{2+}\right]_{\mathrm{i}}$, being $185.34 \pm 3.2 \%$, significantly higher than the value in the control group $(P<0.01)$. This result indicated that $A \beta 25-35$ could increase $\left[\mathrm{Ca}^{2+}\right]_{\mathrm{i}}$, which might contribute to the neurotoxicity of $\mathrm{A} \beta$ seen in cultured hippocampal neurons. Further, we investigated the pretreatment effect of lixisenatide on A $\beta 25-35$ induced $\left[\mathrm{Ca}^{2+}\right]_{\mathrm{i}}$ elevation. As shown in the Figure $4 \mathrm{C}, \mathrm{A} \beta 25-35$-induced elevation of $\left[\mathrm{Ca}^{2+}\right]_{\mathrm{i}}$ level was mostly reversed by lixisenatide $(100 \mu \mathrm{M})$ and the relative fluorescent intensity decreased to $134.01 \pm 2.7 \%(\mathrm{n}=20, P<0.01)$. These results indicated that lixisenatide could protect against $A \beta 25-35$-induced intracellular calcium overloading.

To investigate the molecular mechanism of the protection of lixisenatide against A $325-35$, we also observed the effect of lixisenatide on $A \beta 25-35$-induced $\left[\mathrm{Ca}^{2+}\right]_{\mathrm{i}}$ elevation in the presence of U0126, a MEK1/2 inhibitor. The result showed that treatment with U0126 for $20 \mathrm{~min}$, essentially blocked the protective effect of lixisenatide against A $\beta 25-35$ induced $\left[\mathrm{Ca}^{2+}\right]_{\mathrm{i}}$ elevation. Compared with co-application of lixisenatide and $\mathrm{A} \beta 25-35$, the relative fluorescent intensity in co-application of U0126 $(1 \mathrm{mM})$, lixisenatide $(100 \mu \mathrm{M})$ plus A $325-35$ group increased to $166.18 \pm 3.1 \%(n=20, P<0.01)$. These results indicated that the protective role of lixisenatide against $A \beta 25-35$ induced $\left[\mathrm{Ca}^{2+}\right]_{i}$ elevation might be closely associated with the activation of MEK1/2.

\section{Discussion}

AD is a biologically complex neurodegenerative syndrome. Nearly 20 years ago, with the combination of observations from biochemistry, neuropathology and genetics, a compelling hypothesis known as the amyloid cascade hypothesis was formulated. Although growing amounts of data are inconsistent with the basically linear causal chain of events of this hypothesis (Herrup, 2015), it has been recognized that A $\beta$ plays a key part in the early 
development of the pathogenesis of AD. The amyloid plaque load does not correlate with disease progression at a later stage of disease (Edison et al., 2008). The neurotoxicity of different $A \beta$ fragments such as $A \beta 1-42$ and $A \beta 1-40$ was observed in cell culture first. $A \beta$ peptide- induced cell apoptosis and death in cultured cortical neurons is a common observation (Deshpande et al., 2006). The sequence 25-35 of $\mathrm{A} \beta$ is further recognized as an active site of $A \beta$, as this fragment shows similar neurotoxic properties to the full length of A $\beta$ (Holscher et al., 2007). A $\beta 25-35$ can induce cell apoptosis and necrosis in cultured hippocampal neurons (Sendrowski et al., 2015). Therefore, the present study used A $\beta 25-35$ in primary cell culture and behavioral experiments. For the cell viability assay, mature neurons were exposed to A $\beta 25-35$ for 24 hours. For behavioral memory testing, a Y maze test was performed. The injected solution includes soluble monomers, dimers, and oligomers. It has been proposed that soluble oligomeric forms of $A \beta$ were the chief mediators of cytotoxicity in AD (Ashe and Aguzzi, 2013; Selkoe, 2002; Wisniewski and Goni, 2015). Other configurations of amyloid also can induce neuronal death (Orellana et al., 2011). GLP-1 is an incretin hormone which effectively re-sensitizes insulin signaling and physiological activity by increased expression of the insulin receptor gene (Doyle and Egan, 2007). Another benefit for using GLP-1 in AD treatment is that GLP-1 does not affect blood glucose level in normoglycemic people (Gallwitz, 2006; Vella et al., 2002). However, natural GLP-1 lasts only several minutes in blood plasma because of DPP4-induced degradation (Deacon et al., 1995). Fortunately, many GLP-1 analogues with longer half-life, such as lixisenatide used in the present study, have been developed and even applied to clinical treatment (Elkinson and Keating, 2013; Holst, 2004; Shyangdan et al., 2011).

Memory dysfunction is a prominent symptom of patients with AD (Webster et al., 2014). Spontaneous alternation test of rats with $Y$ maze is a hippocampal dependent short-term spatial working memory (Stuchlik et al., 2014). In the present study, our behavioral results show that bilateral intrahippocampal injection of A $\beta 25-35$ significantly decrease the percentage of alternation of rats, and lixisenatide reversed this detrimental effect. At the same time, the total arm entries of rats did not show any significant 
differences among these groups, suggesting the difference in spontaneous alternation among these groups was due to the change in spatial working memory, but not impairing general locomotor activity of rats.

In cell culture and cell viability experiments, we found that the cell viability of hippocampal cell cultures significantly decreased in A $\beta 25-35$ alone group, which is consistent with the behavioral results in the Y maze test. Interestingly, lixisenatide inhibited A $325-35$-induced cytotoxicity, with a significant viability recovery in the lixisenatide plus A $325-35$ group, compared with A $325-35$ only group. The Akt-MEK1/2 signaling pathway is important for cell survival (Wang et al., 2010). The suppression of the Akt-MEK1/2 signaling pathway would activate the downstream apoptosis pathway and promote cell apoptosis (Cervellati et al., 2014; Nunomura et al., 2001). Accumulation of A $\beta$, which induces cytotoxicity and behavior impairments, may lead to a decrease of the level of Akt and of MEK1/2 activity (Kashour et al., 2003; Ryder et al., 2004). Our experiment shows that lixisenatide prevents the A $\beta 25-35$ induced decrease of pAkt and pMEK1/2 levels, indicating that activation of the Akt-MEK1/2 signaling pathway might be involved in the protective action of lixisenatide against $\mathrm{A} \beta$ toxicity.

A number of studies have shown that perturbed cellular $\mathrm{Ca}^{2+}$ homeostasis may play a prominent role in neuronal death in AD (LaFerla, 2002). The elevation of intracellular calcium mediated the neurotoxicity induced by $\mathrm{A} \beta$ in primary cortical neurons (Fu et al., 2006) and hippocampal neurons (Kelly and Ferreira, 2006). In this study, we observed the effect of $\mathrm{A} \beta 25-35$ on the intracellular $\mathrm{Ca}^{2+}$ level in cultured primary rat hippocampal neurons. Our results showed that A $\beta 25-35$ significantly increased the intracellular $\mathrm{Ca}^{2+}$ level, while lixisenatide pretreatment effectively suppressed $\mathrm{A} \beta 25$-35-induced $\mathrm{Ca}^{2+}$ elevation, demonstrating the association between $A \beta$ and intracellular calcium overload, and suggesting the protection of lixisenatide might be due to alleviating $A \beta$-induced intracellular calcium overload. We further explored the effect of U0126 (a specific MEK1/2 inhibitor, with the cell permeability) in the lixisenatide plus A $\beta 25-35$ group. Our results indicate that the effect of lixisenatide on calcium homeostasis was mostly blocked in the presence of U0126, which might suggest that the MEK1/2 signaling pathway is involved in 
the process of calcium homeostasis. This result confirms our previous cell culture study that demonstrates a normalizing effect of liraglutide in SH-SY5Y cells via activating Akt and MEK1/2 (Sharma et al., 2013). Furthermore, the observed effects explain in part the Neuroprotective effects of lixisenatide in the APP/PS1 mouse model of AD that we have found previously (McClean and Holscher, 2014).

In summary, the present study confirmed the previous reports of the neuroprotective and cytoprotective action of lixisenatide against $A \beta$, suggesting that the protection of lixisenatide may be involved in the activation of Akt-MEK1/2 signaling pathway and the regulation of intracellular calcium homeostasis. 


\section{Figure legends}

Figure 1. Lixisenatide alleviated the detrimental effect induced by Aß25-35 in Y maze working memory test.

A, histograms showing the lower spontaneous alternation of rats after injection of A $\beta 25-35$ $(* * * p<0.001, \mathrm{n}=10)$ and a significant recovery in A $325-35$ plus lixisenatide group $(* * * p<0.001, \mathrm{n}=10) . \mathrm{B}$, histograms showing no significant difference in total arm entries among different groups.

Figure 2. Lixisenatide inhibited the toxicity of Aß25-35 on cultured hippocampal neurons.

Cells were incubated with $A \beta 25-35(10 \mu \mathrm{M})$ in the absence or presence of lixisenatide (100 $\mu \mathrm{M})$ for $24 \mathrm{~h}$. The cell viability and cytotoxicity were tested with CCK-8 and LDH assay, respectively. A, Histograms showing the lower viability of cultured hippocampal neurons in A $\beta 25-35$ plus vehicle group $(n=10)$ and a significant reverse in $A \beta 25-35$ plus lixisenatide group $(\mathrm{n}=10)$. B, Histograms showing the higher toxicity in A $\beta 25-35$ plus vehicle group $(\mathrm{n}=10)$ and a significant recovery in $\mathrm{A} \beta 25-35$ plus lixisenatide group $(\mathrm{n}=10) . * * * p<0.001$

Figure 3. Lixisenatide prevented Aß25-35 induced down regulation of pAKT and pMEK1/2.

A, histograms showing the lower level of pAKT in A $\beta 25-35$ plus vehicle group $(n=10)$ and a significant restoration in $A \beta 25-35$ plus lixisenatide group $(n=10)$. B, histograms showing the decreased level of pMEK1/2 in A $25-35$ plus vehicle group $(n=10)$ and a significant reverse in $\mathrm{A} \beta 25-35$ plus lixisenatide group $(\mathrm{n}=10) .{ }^{*} p<0.05$

Figure 4. Lixisenatide protected against Aß25-35-induced $\left[\mathrm{Ca}^{2+}\right]_{i}$ elevation, which was abolished by U0126. 
A, Representative fluorescent $\left[\mathrm{Ca}^{2+}\right]_{\mathrm{i}}$ imaging of cultured hippocampal neurons a, before A $325-35$ injection; $b, 20 \mathrm{~min}$ after $A \beta 25-35$ injection. Scale length: $20 \mu \mathrm{m}$. B, Plots showing representative fluorescent intensity traces in different groups. C, histograms showing the relative fluorescent intensity 20 min after A $325-35$ injection in different groups. $* * p<0.01$.

\section{References}

Alkam, T., Nitta, A., Mizoguchi, H., Itoh, A., Nabeshima, T., 2007. A natural scavenger of peroxynitrites, rosmarinic acid, protects against impairment of memory induced by Abeta(25-35). Behav Brain Res 180, 139-145.

Arnold, S.E., Hyman, B.T., Flory, J., Damasio, A.R., Van Hoesen, G.W., 1991. The topographical and neuroanatomical distribution of neurofibrillary tangles and neuritic plaques in the cerebral cortex of patients with Alzheimer's disease. Cereb Cortex 1, 103-116.

Ashe, K.H., Aguzzi, A., 2013. Prions, prionoids and pathogenic proteins in Alzheimer disease. Prion 7, 55-59.

Cai, H.Y., Holscher, C., Yue, X.H., Zhang, S.X., Wang, X.H., Qiao, F., Yang, W., Qi, J.S., 2014. Lixisenatide rescues spatial memory and synaptic plasticity from amyloid beta protein-induced impairments in rats. Neuroscience 277C, 6-13.

Cervellati, C., Romani, A., Seripa, D., Cremonini, E., Bosi, C., Magon, S., Passaro, A., Bergamini, C.M., Pilotto, A., Zuliani, G., 2014. Oxidative balance, homocysteine, and uric acid levels in older patients with Late Onset Alzheimer's Disease or Vascular Dementia. J Neurol Sci 337, 156-161.

Christensen, M., Knop, F.K., Vilsboll, T., Holst, J.J., 2011. Lixisenatide for type 2 diabetes mellitus. Expert Opin Investig Drugs 20, 549-557.

Cork, S.C., Richards, J.E., Holt, M.K., Gribble, F.M., Reimann, F., Trapp, S., 2015. Distribution and characterisation of Glucagon-like peptide-1 receptor expressing cells in the mouse brain. Mol Metab 4, 718-731.

Darsalia, V., Mansouri, S., Ortsater, H., Olverling, A., Nozadze, N., Kappe, C., Iverfeldt, K., Tracy, L.M., Grankvist, N., Sjoholm, A., Patrone, C., 2012. Glucagon-like peptide-1 receptor activation reduces ischaemic brain damage following stroke in Type 2 diabetic rats. Clin Sci (Lond) 122, 473-483.

Deacon, C.F., Johnsen, A.H., Holst, J.J., 1995. Degradation of glucagon-like peptide-1 by human plasma in vitro yields an $\mathrm{N}$-terminally truncated peptide that is a major endogenous metabolite in vivo. J Clin Endocrinol Metab 80, 952-957.

Deshpande, A., Mina, E., Glabe, C., Busciglio, J., 2006. Different conformations of amyloid beta induce neurotoxicity by distinct mechanisms in human cortical neurons. J Neurosci 26, 6011-6018.

Doyle, M.E., Egan, J.M., 2007. Mechanisms of action of glucagon-like peptide 1 in the pancreas. Pharmacology \& therapeutics 113, 546-593.

During, M.J., Cao, L., Zuzga, D.S., Francis, J.S., Fitzsimons, H.L., Jiao, X., Bland, R.J., Klugmann, M., Banks, W.A., Drucker, D.J., Haile, C.N., 2003. Glucagon-like peptide-1 receptor is involved in 
learning and neuroprotection. Nature medicine 9, 1173-1179.

Edison, P., Archer, H.A., Gerhard, A., Hinz, R., Pavese, N., Turkheimer, F.E., Hammers, A., Tai, Y.F., Fox, N., Kennedy, A., Rossor, M., Brooks, D.J., 2008. Microglia, amyloid, and cognition in Alzheimer's disease: An [11C](R)PK11195-PET and [11C]PIB-PET study. Neurobiology of disease 32, 412-419.

Elkinson, S., Keating, G.M., 2013. Lixisenatide: first global approval. Drugs 73, 383-391.

Fraser, S.P., Suh, Y.H., Djamgoz, M.B., 1997. Ionic effects of the Alzheimer's disease beta-amyloid precursor protein and its metabolic fragments. Trends Neurosci 20, 67-72.

Fu, H., Li, W., Lao, Y., Luo, J., Lee, N.T., Kan, K.K., Tsang, H.W., Tsim, K.W., Pang, Y., Li, Z., Chang, D.C., Li, M., Han, Y., 2006. Bis(7)-tacrine attenuates beta amyloid-induced neuronal apoptosis by regulating L-type calcium channels. J Neurochem 98, 1400-1410.

Gallwitz, B., 2006. Therapies for the treatment of type 2 diabetes mellitus based on incretin action. Minerva endocrinologica 31, 133-147.

Gault, V., Holscher, C., 2008. GLP-1 agonists facilitate hippocampal LTP and reverse the impairment of LTP induced by beta-amyloid. European journal of pharmacology 587, 112-117.

Gengler, S., McClean, P.L., McCurtin, R., Gault, V.A., Holscher, C., 2012. Val(8)GLP-1 rescues synaptic plasticity and reduces dense core plaques in APP/PS1 mice. Neurobiol Aging 33, 265-276.

Gumuslu, E., Mutlu, O., Celikyurt, I.K., Ulak, G., Akar, F., Erden, F., Ertan, M., 2016. Exenatide enhances cognitive performance and upregulates neurotrophic factor gene expression levels in diabetic mice. Fundam Clin Pharmacol 30, 376-84

Hamilton, A., Holscher, C., 2009. Receptors for the incretin glucagon-like peptide-1 are expressed on neurons in the central nervous system. Neuroreport 20, 1161-1166.

Herrup, K., 2015. The case for rejecting the amyloid cascade hypothesis. Nat Neurosci 18, 794-799.

Holscher, C., 2014a. The incretin hormones glucagonlike peptide 1 and glucose-dependent insulinotropic polypeptide are neuroprotective in mouse models of Alzheimer's disease. Alzheimer's \& dementia : the journal of the Alzheimer's Association 10, S47-S54.

Holscher, C., 2014b. Insulin, incretins and other growth factors as potential novel treatments for Alzheimer's and Parkinson's diseases. Biochemical Society transactions 42, 593-599.

Holscher, C., Gengler, S., Gault, V.A., Harriott, P., Mallot, H.A., 2007. Soluble beta-amyloid[25-35] reversibly impairs hippocampal synaptic plasticity and spatial learning. European journal of pharmacology 561, 85-90.

Holst, J.J., 2004. Treatment of type 2 diabetes mellitus with agonists of the GLP-1 receptor or DPP-IV inhibitors. Expert Opin Emerg Drugs 9, 155-166.

Hunter, K., Holscher, C., 2012a. Drugs developed to treat diabetes, liraglutide and lixisenatide, cross the blood brain barrier and enhance neurogenesis. BMC neuroscience 13, 33-38.

Hunter, K., Holscher, C., 2012b. Drugs developed to treat diabetes, liraglutide and lixisenatide, cross the blood brain barrier and enhance neurogenesis. BMC Neurosci 13, 33.

Iwai, T., Sawabe, T., Tanimitsu, K., Suzuki, M., Sasaki-Hamada, S., Oka, J., 2014. Glucagon-like peptide-1 protects synaptic and learning functions from neuroinflammation in rodents. J Neurosci Res 92, 446-454.

Kashour, T., Burton, T., Dibrov, A., Amara, F.M., 2003. Late Simian virus 40 transcription factor is a target of the phosphoinositide 3-kinase/Akt pathway in anti-apoptotic Alzheimer's amyloid precursor protein signalling. Biochem J 370, 1063-1075. 
Kelly, B.L., Ferreira, A., 2006. beta-Amyloid-induced dynamin 1 degradation is mediated by $\mathrm{N}$-methyl-D-aspartate receptors in hippocampal neurons. J Biol Chem 281, 28079-28089.

LaFerla, F.M., 2002. Calcium dyshomeostasis and intracellular signalling in Alzheimer's disease. Nat Rev Neurosci 3, 862-872.

Li, S., Hong, S., Shepardson, N.E., Walsh, D.M., Shankar, G.M., Selkoe, D., 2009. Soluble oligomers of amyloid Beta protein facilitate hippocampal long-term depression by disrupting neuronal glutamate uptake. Neuron 62, 788-801.

Li, Y., Duffy, K.B., Ottinger, M.A., Ray, B., Bailey, J.A., Holloway, H.W., Tweedie, D., Perry, T., Mattson, M.P., Kapogiannis, D., Sambamurti, K., Lahiri, D.K., Greig, N.H., 2010. GLP-1 receptor stimulation reduces amyloid-beta peptide accumulation and cytotoxicity in cellular and animal models of Alzheimer's disease. J Alzheimers Dis 19, 1205-1219.

Lietzau, G., Nystrom, T., Ostenson, C.G., Darsalia, V., Patrone, C., 2016. Type 2 diabetes-induced neuronal pathology in the piriform cortex of the rat is reversed by the GLP-1 receptor agonist exendin-4. Oncotarget 7, 5865-5876.

Liu, W., Jalewa, J., Sharma, M., Li, G., Li, L., Hölscher, C., 2015. Neuroprotective effects of lixisenatide and liraglutide in the MPTP mouse model of Parkinson's disease. Neuroscience 303, 42-50.

Luchsinger, J.A., Tang, M.X., Shea, S., Mayeux, R., 2004. Hyperinsulinemia and risk of Alzheimer disease. Neurology 63, 1187-1192.

Madsbad, S., Krarup, T., Deacon, C.F., Holst, J.J., 2008. Glucagon-like peptide receptor agonists and dipeptidyl peptidase-4 inhibitors in the treatment of diabetes: a review of clinical trials. Curr Opin Clin Nutr Metab Care 11, 491-499.

McClean, P., Parthsarathy, V., Faivre, E., Hölscher, C., 2011a. The diabetes drug Liraglutide prevents degenerative processes in a mouse model of Alzheimer's disease. The Journal of neuroscience : the official journal of the Society for Neuroscience 31, 6587-6594.

McClean, P.L., Gault, V.A., Harriott, P., Holscher, C., 2010. Glucagon-like peptide-1 analogues enhance synaptic plasticity in the brain: a link between diabetes and Alzheimer's disease. Eur J Pharmacol 630, 158-162.

McClean, P.L., Holscher, C., 2014. Lixisenatide, a drug developed to treat type 2 diabetes, shows neuroprotective effects in a mouse model of Alzheimer's disease. Neuropharmacology 86C, 241-258.

McClean, P.L., Parthsarathy, V., Faivre, E., Holscher, C., 2011b. The diabetes drug liraglutide prevents degenerative processes in a mouse model of Alzheimer's disease. J Neurosci 31, 6587-6594.

Merchenthaler, I., Lane, M., Shughrue, P., 1999. Distribution of pre-pro-glucagon and glucagon-like peptide-1 receptor messenger RNAs in the rat central nervous system. The Journal of comparative neurology 403, 261-280.

Nitta, A., Fukuta, T., Hasegawa, T., Nabeshima, T., 1997. Continuous infusion of beta-amyloid protein into the rat cerebral ventricle induces learning impairment and neuronal and morphological degeneration. Jpn J Pharmacol 73, 51-57.

Nunomura, A., Perry, G., Aliev, G., Hirai, K., Takeda, A., Balraj, E.K., Jones, P.K., Ghanbari, H., Wataya, T., Shimohama, S., Chiba, S., Atwood, C.S., Petersen, R.B., Smith, M.A., 2001. Oxidative damage is the earliest event in Alzheimer disease. J Neuropathol Exp Neurol 60, 759-767. 
Ohara, T., Doi, Y., Ninomiya, T., Hirakawa, Y., Hata, J., Iwaki, T., Kanba, S., Kiyohara, Y., 2011. Glucose tolerance status and risk of dementia in the community: The Hisayama Study. Neurology 77, 1126-1134.

Orellana, J.A., Shoji, K.F., Abudara, V., Ezan, P., Amigou, E., Saez, P.J., Jiang, J.X., Naus, C.C., Saez, J.C., Giaume, C., 2011. Amyloid beta-induced death in neurons involves glial and neuronal hemichannels. J Neurosci 31, 4962-4977.

Parthsarathy, V., Holscher, C., 2013. The type 2 diabetes drug liraglutide reduces chronic inflammation induced by irradiation in the mouse brain. Eur J Pharmacol 700, 42-50.

Perry, T., Haughey, N.J., Mattson, M.P., Egan, J.M., Greig, N.H., 2002a. Protection and reversal of excitotoxic neuronal damage by glucagon-like peptide-1 and exendin-4. J Pharmacol Exp Ther 302, 881-888.

Perry, T., Lahiri, D.K., Chen, D., Zhou, J., Shaw, K.T., Egan, J.M., Greig, N.H., 2002b. A novel neurotrophic property of glucagon-like peptide 1: a promoter of nerve growth factor-mediated differentiation in PC12 cells. J Pharmacol Exp Ther 300, 958-966.

Qi, L., Ke, L., Liu, X., Liao, L., Ke, S., Wang, Y., Lin, X., Zhou, Y., Wu, L., Chen, Z., Liu, L., 2016. Subcutaneous administration of liraglutide ameliorates learning and memory impairment by modulating tau hyperphosphorylation via the glycogen synthase kinase-3beta pathway in an amyloid beta protein induced alzheimer disease mouse model. Eur J Pharmacol 783, 23-32.

Ryder, J., Su, Y., Ni, B., 2004. Akt/GSK3beta serine/threonine kinases: evidence for a signalling pathway mediated by familial Alzheimer's disease mutations. Cell Signal 16, 187-200.

Ryu, J.K., McLarnon, J.G., 2006. Minocycline or iNOS inhibition block 3-nitrotyrosine increases and blood-brain barrier leakiness in amyloid beta-peptide-injected rat hippocampus. Exp Neurol 198, 552-557.

Ryu, J.K., McLarnon, J.G., 2008. Thalidomide inhibition of perturbed vasculature and glial-derived tumor necrosis factor-alpha in an animal model of inflamed Alzheimer's disease brain. Neurobiol Dis 29, 254-266.

Selkoe, D.J., 2001. Alzheimer's disease: genes, proteins, and therapy. Physiol Rev 81, 741-766.

Selkoe, D.J., 2002. Alzheimer's disease is a synaptic failure. Science 298, 789-791.

Sendrowski, K., Sobaniec, W., Stasiak-Barmuta, A., Sobaniec, P., Popko, J., 2015. Study of the protective effects of nootropic agents against neuronal damage induced by amyloid-beta (fragment 25-35) in cultured hippocampal neurons. Pharmacol Rep 67, 326-331.

Sharma, M., Jalewa, J., Holscher, C., 2013. Neuroprotective and anti-apoptotic effects of Liraglutide on SH-SY5Y cells exposed to Methylglyoxal stress. Journal of neurochemistry 128, 459-471.

Shyangdan, D.S., Royle, P., Clar, C., Sharma, P., Waugh, N., Snaith, A., 2011. Glucagon-like peptide analogues for type 2 diabetes mellitus. Cochrane Database Syst Rev, CD006423.

Stepanichev, M.Y., Moiseeva, Y.V., Lazareva, N.A., Gulyaeva, N.V., 2005. Studies of the effects of fragment (25-35) of beta-amyloid peptide on the behavior of rats in a radial maze. Neurosci Behav Physiol 35, 511-518.

Stuchlik, A., Kubik, S., Vlcek, K., Vales, K., 2014. Spatial navigation: implications for animal models, drug development and human studies. Physiol Res 63 Suppl 1, S237-249.

Talbot, K., Wang, H.Y., Kazi, H., Han, L.Y., Bakshi, K.P., Stucky, A., Fuino, R.L., Kawaguchi, K.R., Samoyedny, A.J., Wilson, R.S., Arvanitakis, Z., Schneider, J.A., Wolf, B.A., Bennett, D.A., Trojanowski, J.Q., Arnold, S.E., 2012. Demonstrated brain insulin resistance in Alzheimer's disease patients is associated with IGF-1 resistance, IRS-1 dysregulation, and cognitive decline. 
The Journal of clinical investigation 122, 1316-1338.

Thal, D.R., Rub, U., Orantes, M., Braak, H., 2002. Phases of $A$ beta-deposition in the human brain and its relevance for the development of AD. Neurology 58, 1791-1800.

Vella, A., Shah, P., Reed, A.S., Adkins, A.S., Basu, R., Rizza, R.A., 2002. Lack of effect of exendin-4 and glucagon-like peptide-1-(7,36)-amide on insulin action in non-diabetic humans. Diabetologia 45, 1410-1415.

Vilsboll, T., 2009. Liraglutide: a new treatment for type 2 diabetes. Drugs of today 45, 101-113.

Wang, X., Wang, L., Jiang, R., Yuan, Y., Yu, Q., Li, Y., 2015. Exendin-4 antagonizes Abeta1-42-induced suppression of long-term potentiation by regulating intracellular calcium homeostasis in rat hippocampal neurons. Brain Res 1627, 101-108.

Wang, X., Zheng, W., Xie, J.W., Wang, T., Wang, S.L., Teng, W.P., Wang, Z.Y., 2010. Insulin deficiency exacerbates cerebral amyloidosis and behavioral deficits in an Alzheimer transgenic mouse model. Mol Neurodegener 5, 46.

Webster, S.J., Bachstetter, A.D., Nelson, P.T., Schmitt, F.A., Van Eldik, L.J., 2014. Using mice to model Alzheimer's dementia: an overview of the clinical disease and the preclinical behavioral changes in 10 mouse models. Front Genet 5, 88.

Wisniewski, T., Goni, F., 2015. Immunotherapeutic approaches for Alzheimer's disease. Neuron 85, 1162-1176.

Yan, X.Z., Qiao, J.T., Dou, Y., Qiao, Z.D., 1999. Beta-amyloid peptide fragment 31-35 induces apoptosis in cultured cortical neurons. Neuroscience 92, 177-184.

Yuan, L., Liu, X.J., Han, W.N., Li, Q.S., Wang, Z.J., Wu, M.N., Yang, W., Qi, J.S., 2016. [Gly14]-Humanin Protects Against Amyloid beta Peptide-Induced Impairment of Spatial Learning and Memory in Rats. Neurosci Bull 32, 374-82. 

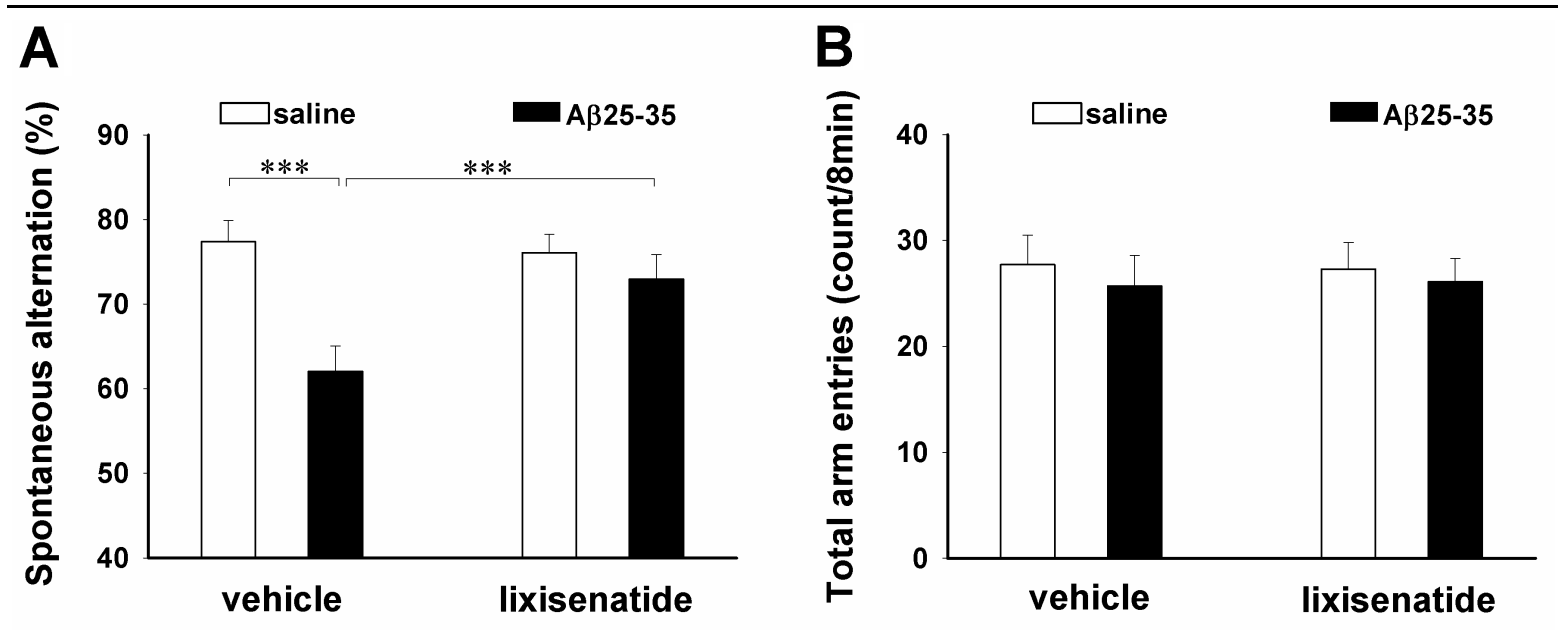

Fig. 1
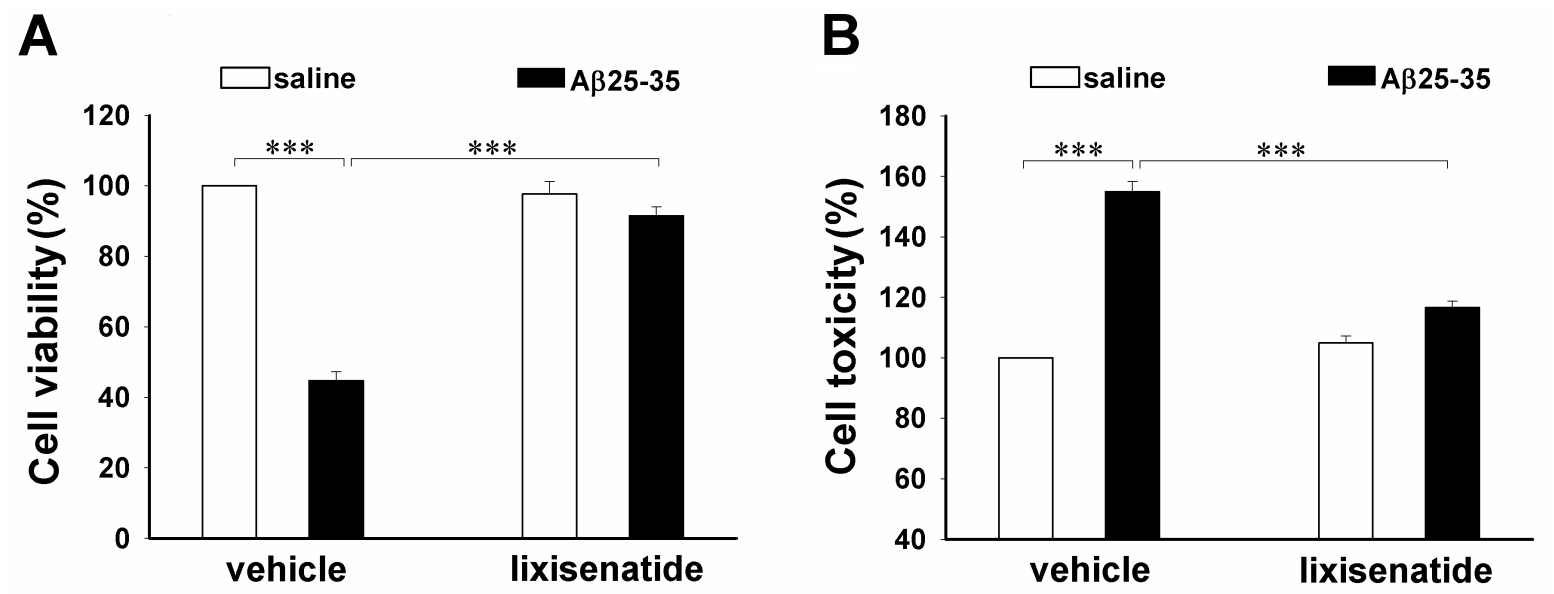

Fig. 2 


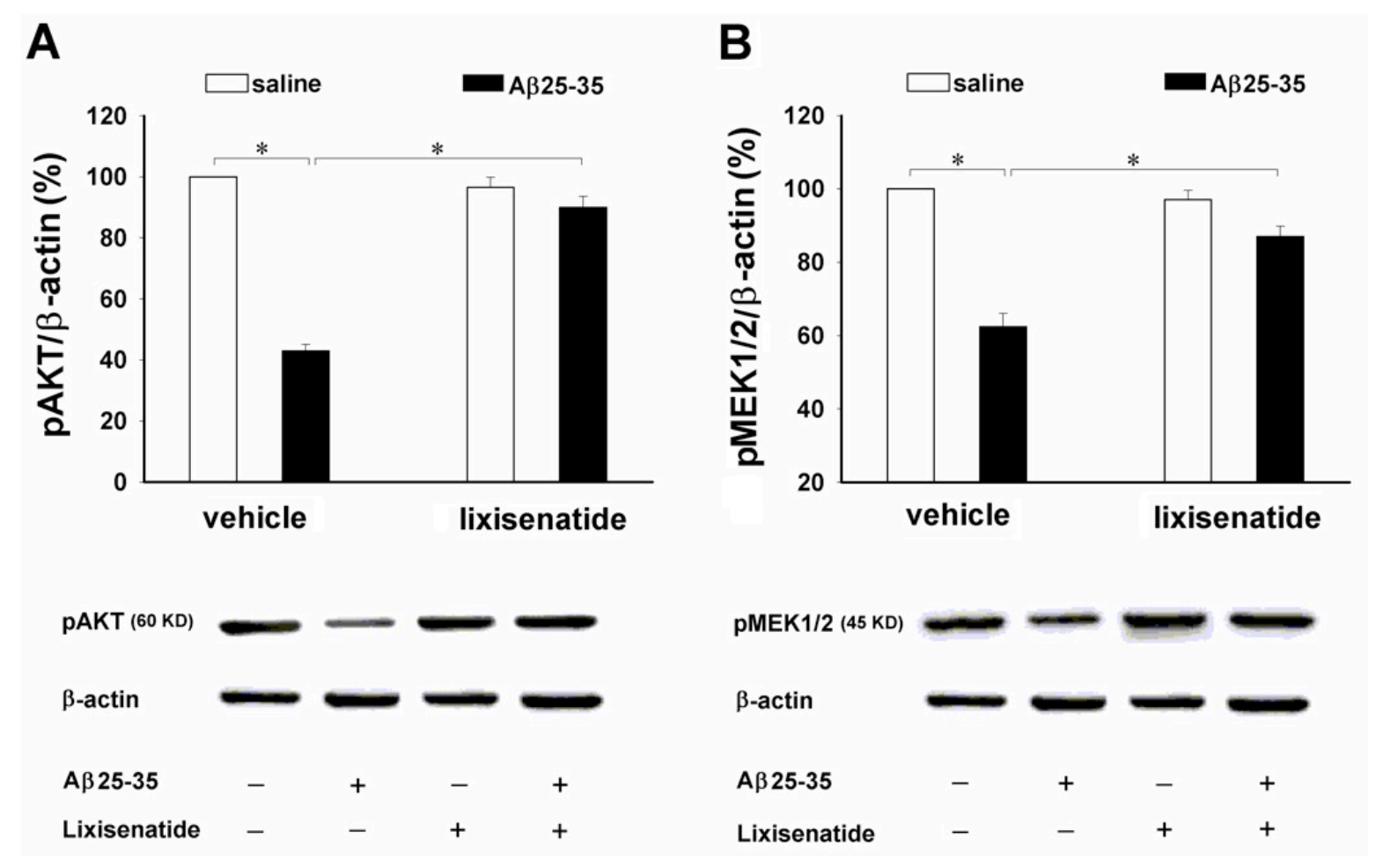

Fig. 3 


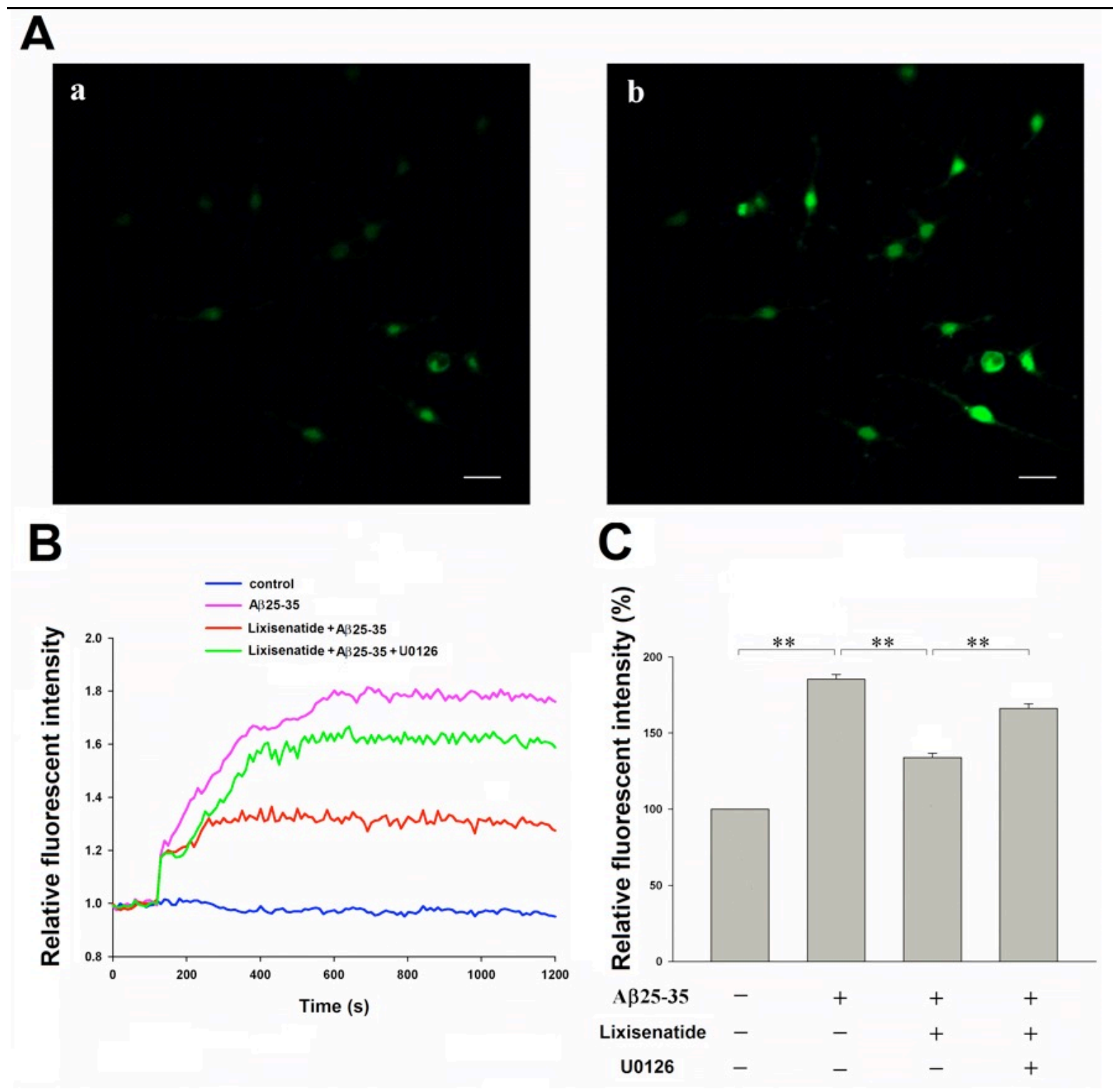

Fig 4 